\title{
latrogenic salt water drowning and the hazards of a high central venous pressure
}

Paul E Marik

\begin{abstract}
Current teaching and guidelines suggest that aggressive fluid resuscitation is the best initial approach to the patient with hemodynamic instability. The source of this wisdom is difficult to discern, however, Early Goal Directed therapy (EGDT) as championed by Rivers et al. and the Surviving Sepsis Campaign Guidelines appears to have established this as the irrefutable truth. However, over the last decade it has become clear that aggressive fluid resuscitation leading to fluid overload is associated with increased morbidity and mortality across a diverse group of patients, including patients with severe sepsis as well as elective surgical and trauma patients and those with pancreatitis. Excessive fluid administration results in increased interstitial fluid in vital organs leading to impaired renal, hepatic and cardiac function. Increased extra-vascular lung water (EVLW) is particularly lethal, leading to iatrogenic salt water drowning. EGDT and the Surviving Sepsis Campaign Guidelines recommend targeting a central venous pressure (CVP) $>8 \mathrm{mmHg}$. A CVP $>8 \mathrm{mmHg}$ has been demonstrated to decrease microcirculatory flow, as well as renal blood flow and is associated with an increased risk of renal failure and death. Normal saline $(0.9 \%$ salt solution) as compared to balanced electrolyte solutions is associated with a greater risk of acute kidney injury and death. This paper reviews the adverse effects of large volume resuscitation, a high CVP and the excessive use of normal saline.
\end{abstract}

Keywords: Fluid; Fluid balance; Normal saline; Lung water; Extra-vascular lung water; Central venous pressure; ICU; Lactate Ringers Solution; Acute respiratory distress syndrome; Sepsis; Mean circulatory filling pressure; Fluid overload

In the critically ill and injured patient, aggressive supportive measures may be harmful and the 'less is more' paradigm appears applicable. In these highly vulnerable patients, more intensive treatments may promote the chances of unwanted adverse effects and hence, iatrogenic injury [1]. Traditional teaching suggests that aggressive fluid resuscitation is the best initial approach for the cardiovascular instability of sepsis. In the Rivers' Early Goal Directed Therapy (EGDT) study, 4.9 liters of crystalloid were given in the first 6 hours and 13.4 liters in the first 72 hours [2]. The Surviving Sepsis Campaign recommends aggressive fluid resuscitation during the first 24 hours of management' [3]. The guidelines for hemodynamic support of sepsis published by the American College of Critical Care Medicine state that large fluid deficits exist in patients with septic shock. Up to 6 to 10 liters of crystalloid solutions may be required for initial resuscitation in the first 24 hours' [4]. Consequently, large

Correspondence: marikpe@evms.edu

Division of Pulmonary and Critical Care Medicine, Eastern Virginia Medical School, 825 Fairfax Av, Suite 410, Norfolk, VA 23507, USA volumes of fluid are often infused in the early stages of sepsis. Traditionally, patients undergoing surgery have been managed with a liberal fluid strategy in which fluids are administered to fill the non-existent 'third space' [5-7]. For patients with traumatic injuries, high volume fluid resuscitation is promoted by the early Advanced Trauma Life Support (ATLS) strategy [8]. There are, however, no human data to show that large volume fluid resuscitation reliably improves organ perfusion $[9,10]$. This approach is likely to lead to iatrogenic salt water drowning with the acute respiratory distress syndrome (ARDS), acute kidney injury (AKI), myocardial injury, gastrointestinal dysfunction, poor wound healing with an increased the risk of death [6,11-21]. Aggressive fluid resuscitation is a wellknown risk factor for secondary intra-abdominal hypertension which in turn is associated with hepatic and respiratory dysfunction, AKI, multiorgan failure and death [22-27]. Current guidelines suggest targeting a central venous pressure (CVP) of 8 to $12 \mathrm{mmHg}$ in patients with severe sepsis and septic shock [28]. However, a high CVP increases venous pressure, increases organ interstitial

\section{实}

(C) 2014 Marik; licensee Springer. This is an Open Access article distributed under the terms of the Creative Commons Attribution License (http://creativecommons.org/licenses/by/4.0), which permits unrestricted use, distribution, and reproduction in any medium, provided the original work is properly cited. 
pressure and reduces organ and microcirculatory flow $[29,30]$. A CVP $>8 \mathrm{mmHg}$ has been associated with an increased risk of renal failure and death [13,16,31]. Normal saline $(0.9 \%$ salt solution) is common resuscitation fluid. However, as compared to balanced electrolyte solutions normal saline (NS) is associated with a greater risk of acute kidney injury and death [32-35]. This paper reviews the adverse effects of large volume resuscitation, a high CVP and the excessive use of normal saline.

\section{Review}

\section{The dangers of large volume resuscitation}

From a pathophysiological point of view, large volume fluid resuscitation in patients with sepsis is illogical and may worsen the hemodynamic derangements of sepsis. Sepsis is primarily a vasoplegic state due to increased production of nitric oxide, activation of $\mathrm{K}_{\mathrm{ATP}}$ channels and vasopressin deficiency [36]. Vasoplegic shock, due to failure of the vascular smooth muscle to constrict, results in arterial and venodilation [36]. Venodilation increases the unstressed vascular compartment, thus decreasing venous return. In patients with septic shock who are fluid responders, vasodilatation with a fall in systematic vascular resistance has been observed following fluid resuscitation $[37,38]$. A similar finding has been noted in an experimental sepsis model [21]. Furthermore, it is important to emphasize that the septic heart responds poorly to fluid loading. In patients with sepsis, the Frank-Starling curve is shifted downwards and to the right, with septic patients showing a diminished response to fluid loading. This observation was demonstrated by Ognibene and colleagues over 25 years ago [39]. Patients in septic shock had a minimal increase in left ventricular stroke work index (LVSWI) in response to volume infusion. This suggests that large volume fluid resuscitation will cause a small increase in stroke volume (with further vasodilatation) at the expense of large increases in filling pressures (increase in both the CVP and left atrial pressures). Furthermore, sepsis is characterized by increased endothelial permeability caused by shedding of the endothelial glycocalyx and the development of gaps between endothelial cells (paracellular leak) [40,41]. An increase in microcirculatory hydrostatic pressure following aggressive fluid resuscitation increases fluid extravasation. Increased cardiac filling pressures following aggressive fluid resuscitation increase the release of natriuretic peptides which act synergistically with nitric oxide causing cGMP mediated vasodilatation [36]. In addition, natriuretic peptides cleave membranebound proteoglycans and glycoproteins (most notably syndecan-1 and hyaluronic acid) off the endothelial glycocalyx [42-44]. This profoundly increases endothelial permeability. Increased natriuretic peptides inhibit the lymphatic propulsive motor activity reducing lymphatic drainage [45-47]. Increased natriuretic peptides following aggressive fluid resuscitation therefore acts to sequestrate fluid into the interstitium. Furthermore, increased filling pressures and a positive fluid balance increase extra-vascular lung water (EVLW) [18]. Increased EVLW impairs gas exchange, reduces lung compliance and increases the work of breathing [18]. Increased EVLW is regarded as a defining feature of acute lung injury/ARDS [48,49]. Increased EVLW is a strong independent predictor of death $[12,18,50,51]$. Due to the endothelial injury, capillary leak and increased hydrostatic pressures less than five percent of infused crystalloid remains intravascular within three hours after infusion resulting in further increases in EVLW and tissue edema [52]. Tissue edema impairs oxygen and metabolite diffusion, distorts tissue architecture, impedes capillary blood flow and lymphatic drainage and disturbs cell-cell interactions; these effects contribute to progressive organ dysfunction [14]. These effects are pronounced in encapsulated organs, such as the liver and kidneys, which lack the capacity to accommodate additional volume without an increase in interstitial pressure, resulting in compromised organ blood flow [14]. This may lead to AKI and hepatic congestion with cholestasis and impaired hepatic function [14]. Myocardial edema due to excess fluid administration compounds the myocardial dysfunction common in critically ill patients [21]. In a cohort of patients requiring mechanical ventilation, Cordemans and colleagues reported significantly more respiratory, liver and cardiovascular organ-failure free days in patients' with a conservative fluid strategy and those whose EVLW fell by more than $2 \mathrm{ml} / \mathrm{kg}$ during their ICU stay [18]. Bowel edema results in malabsorption, ileus and bacterial translocation. In patients with pneumonia, large volume fluid resuscitation may result in severe ARDS (see Figure 1). The chest radiograph series presented in Figure 1 represents a typical case of fatal iatrogenic salt water drowning. This patient was resuscitated according to the EGDT and the Surviving Sepsis Campaign bundles, in which fluids are administered until the CVP $>12 \mathrm{mmHg}[2,28]$.

The harmful effects of aggressive fluid resuscitation on the outcome of sepsis are supported by experimental studies as well as data accumulated from clinical trials [15,20,21,31,51,53-58]. Multiple clinical studies have demonstrated an independent association between an increasingly positive fluid balance and increased mortality in patient with sepsis $[15,18,31,51,53-58]$. In a secondary analysis of the Vasopressin in Septic Shock Trial (VASST), Boyd and colleagues demonstrated that a greater positive fluid balance at both 12 hours and 4 days were independent predictors of death [31]. Furthermore, a number of studies have demonstrated that a positive fluid balance was associated with an increased risk for AKI [15]. Bouchard et al. demonstrated that in 

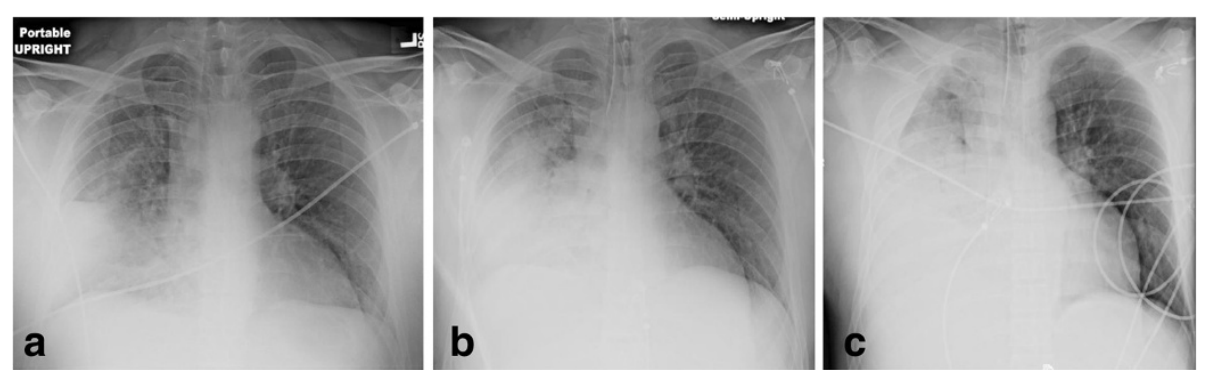

Figure 1 Fourty-four-year old male with Pneumococcal pneumonia. (a) Initial chest radiograph (CXR) in emergency department. (b) CXR four hours later after four liters of crystalloid (patient now intubated). (c) CXR 12 hours after admission, after 9 liters of crystalloid, central venous pressure $(C V P)=10 \mathrm{mmHg}$. Patient died six hours later of refractory hypoxemia.

patients with AKI, fluid overload was independently associated with mortality [58]. In the Fluid and Catheter Treatment Trial (FACTT), the conservative fluid strategy was associated with a trend towards a reduced requirement for renal replacement therapy [59]. The most compelling data that fluid loading in sepsis is harmful come from The Fluid Expansion as Supportive Therapy (FEAST) study performed in 3,141 sub-Saharan children with severe sepsis [60]. In this randomized study, aggressive fluid loading was associated with a significantly increased risk of death. Furthermore, there was no subgroup of patients that benefited from aggressive fluid resuscitation [61].

Emerging data suggest that less than $50 \%$ of septic patients who present to the emergency department (and are fluid naive) will be fluid responsive [62]. In some patients, hypotension and tachycardia do resolve with limited fluid resuscitation. However, fluids alone will not reverse the hemodynamic instability of patients with more severe sepsis; in these patients' fluids alone are likely to exacerbate the vasodilatory shock and increase the capillary leak, tissue edema and organ dysfunction [21]. In the Australasian Resuscitation of Sepsis Evaluation (ARISE) study which used the same entry criteria as the EGDT study, $2.2 \pm 1.9$ liters of fluid were given in the first 6 hours [63]. This compares to 4.9 liters in the intervention arm of the EGDT study [2]. The hospital mortality was $23 \%$ in the ARISE study compared to $30 \%$ in the intervention arm of the EGDT study. This difference in the prescription of fluid is likely due to variability in the management style of severe sepsis between countries. In a survey conducted by Reade et al., intensivists from Australia tended to give less fluid than
Americans with only 15\% of Australians targeting a CVP of 8 to $12 \mathrm{mmHg}$ [64]. In the VASST study optimal survival occurred with a positive fluid balance of approximately three liters at twelve hours [31]. Recently, the Protocolized Care for Early Septic Shock (ProCESS) study was published which compared protocol-based EGDT (Rivers' protocol) and protocol-based standard therapy with usual care [65]. It is noteworthy that the amount of fluid given in the first 6 hours and from 7 to 72 hours was significantly less in the ProCESS EGDT patients than in the Rivers' EGDT patients (see Table 1). As patients were resuscitated according to the same protocol this would appear to be anomalous. However, it should be noted that the mean CVP at 6 hours was $13.8 \pm 4.4 \mathrm{mmHg}$ in the Rivers' EGDT group. Assuming a normal distribution, $50 \%$ of patients in the Rivers' EGDT would have achieved CVPs greater than the mean value of $13.8 \mathrm{mmHg}$. Thus most patients in the Rivers' EGDT study had CVPs outside the stated goal ( $>8$ to 12 $\mathrm{mmHg}$ ). Furthermore, the use of vasopressors in the first six hours of EGDT was significantly greater in ProCESS than in the Rivers' study (see Table 1). We hypothesize that targeting a lower mean CVP in the EGDT arm of the ProCESS trial resulted in less fluid being given and the earlier use of vasopressors. It is therefore possible that the large amount of fluid administered in the Rivers' study partly accounted for the mortality difference between the EGDT arms of the Rivers' and ProCESS studies.

Multiple RCT's and cohort studies have demonstrated that a conservative fluid strategy in patients undergoing elective non-cardiac surgery is associated with significantly fewer complications with a lower mortality (in the

Table 1 Contrasting use of fluids and vasopressors (and mortality) in the Early Goal Directed Therapy (EGDT) arms of the Rivers' and ProCESS studies

\begin{tabular}{lllll}
\hline Study & $\begin{array}{l}\text { Fluid } \mathbf{0} \text { to } \\
\mathbf{6} \text { hours }(\mathbf{m l})\end{array}$ & $\begin{array}{l}\text { Fluid } \mathbf{7} \text { to } \\
\mathbf{7 2} \text { hours }(\mathbf{m l})\end{array}$ & $\begin{array}{l}\text { Fluid } \mathbf{0} \text { to } \\
\mathbf{7 2} \text { hours (ml) }\end{array}$ & $\begin{array}{l}\text { Vasopressors (\%) } \\
\mathbf{0} \text { to } \mathbf{6} \text { hours }\end{array}$ \\
\hline Rivers' EGDT & 4,981 & 8,625 & 13,443 & 27.4 \\
ProCESS EGDT & 2,805 & 4,428 & 7,220 & 54.9 \\
\hline
\end{tabular}


high risk patients) than patients managed with the traditional liberal fluid strategy in which fluids are administered to fill the non-existent 'third space' [5-7]. For patients with traumatic injuries, high volume fluid resuscitation as promoted by the early Advanced Trauma Life Support (ATLS) strategy [8], has given way to a 'damage control' resuscitation strategy [66]. This approach has seen a fall in the volume of crystalloid delivered in the emergency department and an associated fall in mortality. In a prospective analysis of 3,137 trauma patients treated in the Emergency Department, fluid volumes of 1.5 liters or more were significantly associated with mortality [67]. This observation is supported by a metaanalysis which demonstrated in both RCTs and cohort studies that a conservative fluid strategy was associated with a lower mortality in trauma patients [68]. Similarly, an aggressive fluid strategy in the resuscitation of patients with acute pancreatitis has been associated with an increased risk of complications [69].

The results of multiple studies across diverse patient populations have clearly demonstrated that aggressive fluid resuscitation is associated with an increased risk of complications and death. The only published study conducted in adult patients that has demonstrated that early aggressive fluid resuscitation improves outcome is the EGDT study by Rivers et al. [2]. However, the results of this study do not appear to be biologically plausible (implausible effect size) [70], the elements of the protocol were not based on evidence-based interventions [71], the analysis of the results of study has come under scrutiny [72], and the results were not validated in a large randomized controlled trial [65]. While hypovolemia will result in decreased cardiac output (and blood pressure) with inadequate organ perfusion leading to organ dysfunction, overzealous fluid resuscitation and hypervolemia induces a cascade of events that similarly results in organ dysfunction. From an evolutionary point of view, humans have evolved to deal with hypovolemia and not hypervolemia. Hypervolemia is a recent (last 20 years) and largely iatrogenic phenomenon. The argument is no longer 'wet or dry' but 'just the right amount of fluid' $[73,74]$.

\section{The dangers of a high CVP}

Not only has the CVP failed as a useful measure for the assessment of preload and fluid responsiveness [75], but a CVP $>8 \mathrm{mmHg}$ is independently associated with a higher mortality and increased risk of AKI in patients with sepsis and heart failure $[13,31,76]$. This suggests that the CVP component of the six-hour resuscitation bundle as widely promoted by the Surviving Sepsis Campaign may lead to harm [28]. It is important to note that a normal CVP is close to zero and not 8 to $12 \mathrm{mmHg}$ as the Surviving Sepsis Campaign might lead one to believe [28]. The mean circulatory filling pressure (MCFP) is regarded as the driving pressure that determines venous return and is considered synonymous with the effective circulatory blood volume [77-81]. The MCFP is conceptualized as the pressure distending the vasculature when the heart is stopped (zero flow) and the pressures in all segments of the circulatory system have equalized [78-80]. The MCFP in humans is normally in the range of 8 to $10 \mathrm{mmHg}$ [80]. According to Guyton, venous return is determined by the gradient between MCFP and CVP [78]. An increase in the CVP or a fall in the MCFP will reduce venous return, stroke volume and cardiac output. Cecconi and colleagues investigated the relationship between the changes in MCFP with the change in CVP and stroke volume following a fluid challenge in postsurgical ICU patients [82]. In this study MCFP increased equally in fluid responders and non-responders (3.1 \pm 1.9 versus $3.1 \pm 1.8 \mathrm{mmHg}$ ). However, the increase in the CVP was greater in the non-responders than the responders. This study emphasizes that a disproportionate increase in the CVP will impede venous return and cardiac output [81].

In addition to influencing venous return, a high CVP is transmitted backwards increasing venous pressure. The increase in venous pressure has a profound effect on microcirculatory flow and organ function. The kidney is particularly affected by congestion and increased venous pressure, which leads to increased renal subcapsular pressure and lowered renal blood flow and glomerular filtration rate (GFR) [83]. Furthermore, increased renal interstitial pressure may collapse intrarenal collecting lymphatics which compromise lymph flow [84]. The detrimental effect of high venous pressure on renal function was established by FR Winton in an elegant set of experiments performed in 1930s [29]. This investigator attached the kidneys of a dog to a heart-lung circulation by means of cannulae inserted into the artery and veins of the kidneys and then independently altered venous and arterial pressure. Dr Winton demonstrated that increasing venous pressure dramatically decreased urine production. More recently, Legrand and colleagues investigated the association between hemodynamic variables and AKI in patients with sepsis [13]. In this study, the CVP was the only hemodynamic variable associated with the development of AKI; cardiac output, mixed venous oxygen saturation $\left(\mathrm{ScvO}_{2}\right)$ and mean arterial pressure (MAP) were unable to predict the development of AKI. These authors noted a linear relationship between increasing CVP and AKI; there was a trend for higher CVP to be associated with worse renal outcome for all levels of CVP above $4 \mathrm{mmHg}$, with a CVP of 15 $\mathrm{mmHg}$ being associated with an $80 \%$ risk of new or persistent AKI, compared to approximately $30 \%$ at a CVP of $6 \mathrm{mmHg}$. Van Biesen and colleagues demonstrated that septic patients developing AKI had a higher positive fluid balance, a higher CVP and worse oxygenation than 
septic patients without AKI [16]. It is important to point out that these are observational data, and that it is likely that other factors play a role in the pathophysiology of AKI in sepsis. In patients with acute decompensated heart failure, Mullens et al. demonstrated a near linear relationship between increasing CVP and worsening renal function [76]. In this study, worsening renal function occurred significantly less frequently in patients with a CVP $<8 \mathrm{mmHg}$. Furthermore, similar to the findings of Legrand and colleagues, the CVP was the only hemodynamic parameter that predicted worsening renal failure, with the cardiac index, systolic blood pressure and pulmonary capillary wedge pressure being similar between those patients who maintained renal function as compared to those with worsening renal function. In a subanalysis of the Evaluation Study of Congestive Heart Failure and Pulmonary Artery Catheterization Effectiveness trial (ESCAPE), Nohria et al. demonstrated a significant correlation between baseline renal function and the CVP, there was, however no correlation between baseline renal function and cardiac index, pulmonary capillary wedge pressure or systemic vascular resistance [85]. These data suggest that a high CVP independently increases the risk for 'congestive kidney failure'. Most clinicians fluid load patients with oliguria; this intervention sets into motion a vicious cycle, with fluid loading further increasing renal venous pressure with a further decline in renal function and urine output [16].

In addition to increasing renal venous and interstitial pressure, a high CVP will result in an increase in hepatic and intestinal venous pressure causing hepatic and intestinal congestion and impaired microcirculatory flow. Indeed, in a study of 70 patients with sepsis, Vellinga and colleagues demonstrated that the sublingual microvascular flow index (MFI) and percentage of perfused vessels (PPV) was significantly lower with a patients with a high CVP (>12 $\mathrm{mmHg}$ ) than a low CVP: $1.44 \pm 0.94$ versus $1.89 \pm 0.91, P=0.006$; and $88 \pm 21$ versus $95 \pm 8 \%, P=$ 0.006) [30]. The cardiac index, MAP and perfusion pressure (MAP-CVP) did not differ significantly between the high and low CVP groups. In a multivariate logistic regression analysis, the only significant predictor for an abnormal MFI was a CVP > $12 \mathrm{mmHg}$. Because microcirculatory driving pressure is the difference between post-arteriolar and venular pressure, a relatively mild increase in CVP may considerably influence the capillary perfusion pressure and microcirculatory flow [30]. As the pressure drop in the vascular system occurs upstream at the level of small arterioles (resistance vessels), the microcirculation is considered a low pressure compartment. Therefore, mean capillary pressure is much closer to venous than to arterial pressure. Therefore, as long as the MAP is within an organ's autoregulatory range, the CVP becomes the major determinant of capillary blood flow. This suggests that venous pressure has a much greater effect on microcirculatory flow than the MAP. The adverse consequences of volume overload and a high CVP are summarized listed below

\section{Consequences of volume overload}

Pulmonary edema and increased extra-vascular lung water
Impaired oxygenation
Altered pulmonary and chest wall mechanics
Increased work of breathing
Myocardial edema
Decreased contractility
Diastolic dysfunction
Conduction defects
Increased intraabdominal pressure
Acute kidney injury
Hepatic dysfunction
Decreased lung volumes
Ileus
Gastrointestinal
Ileus
Malabsorption
Bacterial translocation
Hepatic congestion
Decreased wound healing

\section{Consequences of a high central venous pressure}

Decreased venous return and stroke volume Acute kidney injury

Hepatic congestion

Decreased splanchnic microcirculatory flow

\section{The dangers of a normal saline}

Despite differences in composition between normal saline $(0.9 \% \mathrm{NaCl})$ and Lactated Ringer's (LR), Normosol, Isolyte and Plasmalyte solutions, they are frequently considered physiologically equivalent. Whilst no body fluid has an electrolyte composition similar to that of normal saline (NS), this fluid is frequently referred to as 'physiologic salt solution (PSS)'. However, $0.9 \% \mathrm{NaCl}$ is more correctly known as 'Unphysiologic Salt Solution'. Experimental and clinical data have clearly demonstrated that these fluids are not physiologically equivalent. Only LR, Normosol, Isolyte and Plasmalyte solutions are balanced salt solutions. Due to the calcium content of LR (and not Plasmalyte), it has been traditionally taught that LR should not be infused in the same venous line as blood (may activate clotting). However, this is not true [86].

\section{Renal failure}

The increased chloride load delivered to the macula densa results in afferent arterial constriction [87]. In health 
volunteers, NS significantly reduces renal arterial flow and renal cortisol tissue perfusion as compared to Plasmalyte [88]. In a sequential cohort study Yunos and colleagues demonstrated that a chloride liberal fluid (NS) was associated with a much higher incidence of renal failure than critically patients resuscitated with a chloride restrictive fluid (LR and Plasmalyte) [32].

\section{Hyperchloremic metabolic acidosis and death}

Numerous studies have demonstrated the development of a hyperchloremic metabolic acidosis in human volunteers and patients resuscitated with NS [89-92]. The additional loss (renal) of $\mathrm{HCO}_{3}$ in the setting of reduced buffering capacity only adds to the acid-base burden characteristic of hypoperfused states [90]. Furthermore, resuscitation with NS may produce a 'dilutional acidosis'. In both experimental and clinical (pancreatitis) studies, hyperchloremic acidosis has been demonstrated to increase the release of inflammatory mediators [93,94]. In a prospective cohort study, Boniatti et al. demonstrated that hyperchloremia was an independent predictor of death [95]. Similarly, in two large cohorts of patients undergoing non-cardiac surgery, hyperchloremia was an independently associated with increased morbidity and mortality [33,34]. In these studies the risk of death increased with increasing chloride levels. Using a large multi-institutional database, Raghunathan et al. performed propensity score matching in patients with severe sepsis comparing resuscitation with balanced solutions versus NS [35]. In this study, resuscitation with a balanced solution was associated with a lower inhospital mortality (19.6\% versus $22.8 \%$; relative risk (RR) 0.86 ; $95 \%$ CI, 0.78 to 0.94 ).

\section{Coagulopathy}

Studies in surgical patients have demonstrated that as compared to LR, volume replacement with NS results in greater blood loss with a greater need for blood transfusion [91]. The cause of the coagulopathy is unclear, and is only partly explained by the difference in calcium between the two solutions.

\section{Lactate as a metabolic fuel}

It is not an accidental quirk of nature that the body produces lactate during stress states. The proportion of lactate uptake by the myocardium and its use a metabolic fuel increases during exercise, $\beta$-adrenergic stimulation and shock [96-98]. During shock the heart undergoes a major shift in substrate utilization such that it oxidizes lactate for the majority of its energy needs [98]. Revelly and coworkers demonstrated that an infusion of sodium lactate increased cardiac performance in patients with both cardiogenic and septic shock [99]. Similarly, during increased demand on brain metabolism, lactate is increasingly utilized as an energy substrate [100-102]. LR may therefore have additional advantages in shocked patients with the lactate being oxidized and serving as a source of energy $[103,104]$.

\section{Conclusions}

A liberal fluid resuscitation strategy, a $C V P>$ than 8 $\mathrm{mmHg}$ and the use of $0.9 \% \mathrm{NaCl}$ as the predominant resuscitation fluid are all associated with an increased risk of renal failure, respiratory failure, gastrointestinal dysfunction and death across a broad spectrum of clinical disorders. These three treatment strategies probably act synergistically to harm patients, forming the 'Deadly Trio'.

\section{Abbreviations}

AKI: acute kidney injury; ARDS: acute respiratory distress syndrome; ARISE: Australasian Resuscitation of Sepsis Evaluation trial; ATLS: Advanced Trauma Life Support; CVP: central venous pressure; CXR: chest radiograph; EGDT: Early Goal Directed Therapy; ESCAPE: Evaluation Study of Congestive Heart Failure and Pulmonary Artery Catheterization Effectiveness trial; EVLW: extra-vascular lung water; FACTT: Fluid and Catheter Treatment Trial; FEAST: The Fluid Expansion as Supportive Therapy study; GFR: glomerular filtration rate; LR: Lactated Ringer's solution; MAP: mean arterial pressure; MCFP: mean circulatory filling pressure; NS: normal saline; ProCESS: Protocolized Care for Early Septic Shock trial; RR: relative risk; $\mathrm{ScvO}_{2}$ : mixed venous oxygen saturation; VASST: Vasopressin in Septic Shock Trial.

\section{Competing interest}

The author has no real or perceived conflicts of interest or a financial interest in any of the products mentioned in this paper.

\section{Authors' contribution}

The author solely contributed to this paper and assumes full responsibility for the content of the paper.

Received: 2 April 2014 Accepted: 27 May 2014

Published online: 21 June 2014

\section{References}

1. Knox M, Pickkers P: 'Less is More' in critically ill patients. Not too intensive. JAMA Intern Med 2013, 173:1369-1372.

2. Rivers E, Nguyen B, Havstad S, Ressler J, Muzzin A, Knoblich B, Peterson E, Tomlanovich M: Early goal-directed therapy in the treatment of severe sepsis and septic shock. N Engl J Med 2001, 345:1368-1377.

3. Dellinger RP, Carlet JM, Masur H, Gerlach H, Calandra T, Cohen J, GeaBanacloche J, Keh D, Marshall JC, Parker MM, Ramsay G, Zimmerman JL, Vincent JL, Levy MM: Surviving Sepsis Campaign guidelines for management of severe sepsis and septic shock. Crit Care Med 2004, 32:858-873.

4. Hollenberg SM, Ahrens TS, Annane D, Astiz ME, Chalfin DB, Dasta JF, Heard SO, Martin C, Napolitano LM, Susla GM, Totaro R, Vincent JL, ZanottiCavazzoni S: Practice parameters for hemodynamic support of sepsis in adult patients: 2004 update. Crit Care Med 2004, 32:1928-1948.

5. Cecconi M, Corredor C, Arulkumaran N, Abuella G, Ball J, Grounds RM, Hamilton M, Rhodes A: Clinical review: goal-directed therapy-what is the evidence in surgical patients? The effect on different risk groups. Crit Care 2013, 17:209.

6. Corcoran T, Rhodes JE, Clarke S, Myles PS, Ho KM: Perioperative fluid management strategies in major surgery: a stratified meta-analysis. Anesth Analg 2012, 114:640-651.

7. Jacob M, Chappell D, Rehm M: The 'third space' - fact or fiction? Best practice research Clin Anesthesiol 2009, 23:145-157.

8. Initial Assessment and Managment: Advanced Trauma Life Support for Doctors; Student Course Manual. Chicago: American College of Surgeons; 1997:21-46.

9. Hilton AK, Bellomo R: A critique of fluid bolus resuscitation in severe sepsis. Crit Care 2012, 16:302. 
10. Hilton AK, Bellomo R: Totem and taboo: fluids in sepsis. Crit Care 2011, $15: 164$.

11. LeTourneau JL, Pinney J, Phillips CR: Extravascular lung water predicts progression to acute lung injury in patients with increased risk. Crit Care Med 2012, 40:847-854

12. Jozwiak M, Silva S, Persichini R, Anguel N, Osman D, Richard C, Teboul JL, Monnet $X$ : Extravascular lung water is an independent prognostic factor in patients with acute respiratory distress syndrome. Crit Care Med 2013, 41:472-480

13. Legrand M, Dupuis C, Simon C, Gayat E, Mareo J, Lukaszewicz AC, Payen D: Association between systemic hemodynamics and septic kidney injury in critically ill patients: a retrospective observational study. Crit Care 2013, 17:R278.

14. Prowle JR, Echeverri JE, Ligabo EV, Ronco C, Bellomo R: Fluid balance and acute kidney injury. Nat Rev Nephrol 2010, 6:107-115.

15. Payen D, De Pont AC, Sakr Y, Spies C, Reinhart K, Vincent JL: A positive fluid balance is associated with a worse outcome in patients with acute renal failure. Crit Care 2008, 12:R74

16. Van Biesen W, Yegenaga I, Vanholder R, Verbeke F, Hoste E, Colardyn F, Lameire N: Relationship between fluid status and its management on acute renal failure (ARF) in intensive care unit (ICU) patients with sepsis: a prospective analysis. J Nephrol 2005, 18:54-60

17. Wang $\mathrm{CH}$, Hsieh WH, Chou HC, Huang YS, Shen JH, Yeo YH, Chang HE: Liberal versus restricted fluid resuscitation strategies in trauma patients: a systematic review and meta-analysis of randomized controlled trials and observational studies. Crit Care Med 2014, 42:954-961.

18. Cordemans C, De Laet I, Van Regenmortel N, Schoonheydt K, Dits H, Huber W, Malbrain ML: Fluid management in critically ill patients: the role of extravascular lung water, abdominal hypertension, capillary leak, and fluid balance. Ann Intensive Care 2012, 2:S1.

19. Arulkumaran N, Corredor C, Hamilton MA, Ball J, Grounds RM, Rhodes A, Cecconi M: Cardiac complications associated with goal-directed therapy in high-risk surgical patients: a meta-analysis. Br J Anaesth 2014, 112:648-659.

20. Brandt S, Regueira T, Bracht H, Porta F, Djafarzadeh S, Takala J, Gorrasi J, Borotto E, Krejci V, Hiltebrand LB, Bruegger LE, Beldi G, Wilkens L, Lepper PM, Kessler U, Jakob SM: Effect of fluid resuscitation on mortality and organ function in experimental sepsis models. Crit Care 2009, 13:R186.

21. Rehberg S, Yamamoto $Y$, Sousse L, Bartha E, Jonkam C, Hasselbach AK, Traber LD, Cox RA, Westphal M, Enkhbaatar P, Traber DL: Selective V(1a) agonism attenuates vascular dysfunction and fluid accumulation in ovine severe sepsis. Am J Physiol Heart Circ Physiol 2012, 303:H1245-H1254.

22. Malbrain ML, Chiumello D, Pelosi P, Bihari D, Innes R, Ranieri VM, Del TM, Wilmer A, Brienza N, Malcangi V, Cohen J, Japiassu A, De Keulenaer BL, Daelemans R, Jacquet L, Laterre PF, Frank G, De Souza P, Cesana B, Gattinoni L: Incidence and prognosis of intraabdominal hypertension in a mixed population of critically ill patients: a multiple-center epidemiological study. Crit Care Med 2005, 33:315-322.

23. Kirkpatrick AW, Roberts DJ, De WJ, Jaeschke R, Malbrain ML, De KB, Duchesne J, Bjorck M, Leppaniemi A, Ejike JC, Sugrue M, Cheatham M, Ivatury R, Ball CG, Reintam BA, Regli A, Balogh ZJ, D'Amours S, Debergh D, Kaplan M, Kimball E, Olvera C: Intra-abdominal hypertension and the abdominal compartment syndrome: updated consensus definitions and clinical practice guidelines from the World Society of the Abdominal Compartment Syndrome. Intensive Care Med 2013, 39:1190-1206.

24. Dalfino L, Tullo L, Donadio I, Malcangi V, Brienza N: Intra-abdominal hypertension and acute renal failure in critically ill patients. Intensive Care Med 2008, 34:707-713

25. Diebel LN, Wilson RF, Dulchavsky SA, Saxe J: Effect of increased intraabdominal pressure on hepatic arterial, portal venous, and hepatic microcirculatory blood flow. J Trauma 1992, 33:279-282.

26. El D, Liang H, Taichman D, Hansen-Flaschen J, Fuchs BD: Abdominal compartment syndrome is common in medical intensive care unit patients receiving large-volume resuscitation. J Intensive Care Med 2007, 22:294-299.

27. Malbrain ML, Viaene D, Kortgen A, De Laet I, Dits H, Van RN, Schoonheydt K, Bauer M: Relationship between intra-abdominal pressure and indocyanine green plasma disappearance rate: hepatic perfusion may be impaired in critically ill patients with intra-abdominal hypertension. Ann Intensive Care 2012, 2(Suppl 1):S19.

28. Dellinger RP, Levy MM, Rhodes A, Annane D, Gerlach H, Opal SM, Sevransky JE, Sprung CL, Douglas IS, Jaeschke R, Osborn TM, Nunnally ME, Townsend SR, Reinhart K, Kleinpell RM, Angus DC, Deutschman CS, Machado FR,
Rubenfeld GD, Webb SA, Beale RJ, Vincent JL, Moreno R: Surviving Sepsis Campaign: International Guidelines for Management of Severe Sepsis and Septic Shock: 2012. Crit Care Med 2013, 41:580-637.

29. Winton FR: The influence of venous pressure on the isolated mammalian kidney. J Physio/ 1931, 72:49-61

30. Vellinga NA, Ince C, Boerma EC: Elevated central venous pressure is associated with impairment of microcirculatory blood flow in sepsis. BMC Anesthesiol 2013, 13:17.

31. Boyd JH, Forbes J, Nakada T, Walley KR, Russell JA: Fluid resuscitation in septic shock: a positive fluid balance and elevated central venous pressure increase mortality. Crit Care Med 2011, 39:259-265.

32. Yunos NM, Bellomo R, Hegarty C, Stoty D, Ho L, Bailey M: Association between a chloride-liberal versus chloride-restrictive intravenous fluid administration strategy and kidney injury in critically ill adults. JAMA 2012, 308:1566-1572.

33. McCluskey SA, Karkouti K, Wijeysundera D, Minkovich L, Tait G, Beattie WS: Hyperchloremia after noncardiac surgery is independently associated with increased morbidity and mortality: a propensity-matched cohort study. Anesth Analg 2013, 117:412-421.

34. Shaw AD, Bagshaw SM, Goldstein SL, Scherer LA, Duan M, Schermer CR, Kellum JA: Major complications, mortality, and resource utilization after open abdominal surgery: $0.9 \%$ saline compared to Plasma-Lyte. Ann Surg 2012, 255:821-829.

35. Raghunathan K, Shaw A, Nathanson B, Sturmer T, Brookhart A, Stefan MS, Setoguchi S, Beadles C, Lindenauer PK: Association between the choice of IV crystalloid and in-hospital mortality among critically ill adults with sepsis. Crit Care Med 2014, 42:1585-1591.

36. Landry DW, Oliver JA: Pathogenesis of vasodilatory shock. N Engl J Med 2001, 345:588-595

37. Pierrakos C, Velissaris D, Scolletta S, Heenen S, De BD, Vincent JL: Can changes in arterial pressure be used to detect changes in cardiac index during fluid challenge in patients with septic shock? Intensive Care Med 2012, 38:422-428.

38. Monnet X, Chemla D, Osman D, Anguel N, Richard C, Pinsky MR, Teboul JL: Measuring aortic diameter improves accuracy of esophageal Doppler in assessing fluid responsiveness. Crit Care Med 2007, 35:477-482

39. Ognibene FP, Parker MM, Natanson C, Shelhamer JH, Parrillo JE: Depressed left ventricular performance: response to volume infusion in patients with sepsis and septic shock. Chest 1988, 93:903-910.

40. Goldenberg NM, Steinberg BE, Slutsky AS, Lee WL: Broken barriers: a new take on sepsis pathogenesis. Sci Transl Med 2011, 3:88ps25.

41. London NR, Zhu W, Bozza FA, Smith MC, Greif DM, Sorensen LK, Chen L, Kaminoh Y, Chan AC, Passi SF, Day CW, Barnard DL, Zimmerman GA Krasnow MA, Li DY: Targeting Robo4-dependent Slit signaling to survive the cytokine storm in sepsis and influenza. Sci Trans/ Med 2010, 2:23ra19.

42. Bruegger D, Jacob M, Rehm M, Loetsch M, Welsch U, Conzen P, Becker BF: Atrial natriuretic peptide induces shedding of endothelial glycocalyx in coronary vascular bed of guinea pig hearts. Am J Physiol Heart Circ Physiol 2005, 289:H1993-H1999.

43. Berg S, Golster M, Lisander B: Albumin extravasation and tissue washout of hyaluronan after plasma volume expansion with crystalloid or hypooncotic colloid solutions. Acta Anaesthesiol Scand 2002, 46:166-172.

44. Bruegger D, Schwartz L, Chappell D, Jacob M, Rehm M, Vogeser M, Christ F, Reichart B, Becker BF: Release of atrial natriuretic peptide precedes shedding of the endothelial glycocalyx equally in patients undergoing on- and offpump coronary artery bypass surgery. Basic Res Cardiol 2011, 106:1111-1121.

45. Atchison DJ, Johnston MG: Atrial natriuretic peptide attenuates flow in an isolated lymph duct preparation. Eur J Physiol 1996, 431:618-624.

46. Anderson WD, Kulik TJ, Mayer JE, Anderson WD, Kulik TJ, Mayer JE: Inhibition of contraction of isolated lymphatic ducts by atrial natriuretic peptide. Am J Physiol 1991, 260:R610-R614.

47. Ohhashi T, Watanabe N, Kawai Y, Ohhashi T, Watanabe N, Kawai Y: Effects of atrial natriuretic peptide on isolated bovine mesenteric lymph vessels. Am J Physiol 1990, 259:H42-H47.

48. Tagami T, Sawabe M, Kushimoto S, Marik PE, Mieno MN, Kawaguchi T, Kusakabe T, Tosa R, Yokota H, Fukuda Y: Quantitative diagnosis of diffuse alveolar damage using extravascular lung water. Crit Care Med 2013, 41:2144-2150

49. Michard F, Fernandez-Mondejar E, Kirov M, Malbrain M, Tagami T: A new and simple definition for acute lung injury. Crit Care Med 2012, 40:1004-1006 
50. Sakka SG, Klein M, Reinhart K, Meier-Hellmann A: Prognostic value of extravascular lung water in critically ill patients. Chest 2002, 122:2080-2086.

51. Chung FT, Lin SM, Lin SY, Lin HC: Impact of extravascular lung water index on outcomes of severe sepsis patients in a medical intensive care unit. Respir Med 2008, 102:956-961.

52. Bark BP, Persson J, Grande PO: Importance of the infusion rate for the plasma expanding effect of $5 \%$ albumin, $6 \%$ HES 130/0.4, $4 \%$ gelatin and $0.9 \% \mathrm{NaCl}$ in the septic rat. Crit Care Med 2013, 41:857-866.

53. Rosenberg AL, Dechert RE, Park PK, Bartlett RH: Review of a large clinical series: association of cumulative fluid balance on outcome in acute lung injury: a retrospective review of the ARDSnet tidal volume study cohort. J Intensive Care Med 2009, 24:35-46.

54. Micek SC, McEnvoy C, McKenzie M, Hampton N, Doherty JA, Kollef MH: Fluid balance and cardiac function in septic shock as predictors of hospital mortality. Crit Care 2013, 17:R246.

55. Vincent JL, Sakr Y, Sprung CL, Ranieri VM, Reinhart K, Gerlach H, Moreno R, Carlet J: Sepsis in European intensive care units: results of the SOAP study. Crit Care Med 2006, 34:344-353

56. Alsous F, Khamiees M, De Girolamo A, Moateng-Adjepong Y, Manthous CA Negative fluid balance predicts survival in patients with septic shock: a retrospective pilot study. Chest 2000, 117:1749-1754.

57. Murphy CV, Schramm GE, Doherty JA, Reichley RM, Gajic O, Afessa B, Micek ST, Kollef $\mathrm{MH}$ : The importance of fluid management in acute lung injury secondary to septic shock. Chest 2009, 136:102-109.

58. Bouchard J, Soroko SB, Chertow GM, Himmelfarb J, Ikizler TA, Paganini EP, Mehta RL: Fluid accumulation, survival and recovery of kidney function in critically ill patients with acute kidney injury. Kidney Int 2009, 76:422-427.

59. The ARDSnet Investigators: Comparison of two fluid-management strategies in acute lung injury. N Engl J Med 2006, 354:2564-2575.

60. Maitland K, Kiguli S, Opoka RO, Engoru C, Olupot-Olupot P, Akech SO, Nyeko $R$, Mtove G: Mortality after fluid bolus in African children with severe infection. N Engl J Med 2011, 364:2483-2495.

61. Maitland K, George EC, Evans JA, Kiguli S, Olupot-Olupot P, Akech SO, Opoka RO, Engoru C, Nyeko R, Mtove G, Reyburn H, Brent B, Nteziyaremye J, Mpoya A, Prevatt N, Dambisya CM, Semakula D, Ddungu A, Okuuny V, Wokulira R, Timbwa M, Otii B, Levin M, Crawley J, Babiker AG, Gibb DM: Exploring mechanisms of excess mortality with early fluid resuscitation: insights from the FEAST trial. BMC Med 2013, 11:68

62. Smith B, Phillips R, Madigan V, West M: Decreased mortality, morbidity and emergency transport in septic shock: a new protocol based on advanced noninvasive haemodynamics and early antibiotics [abstract]. Crit Care Med 2013, doi:10.1097/01.ccm.0000425236.44389.af

63. Peake SL, Bailey M, Bellomo R, Cameron PA, Cross A, Delaney A, Finfer S, Higgins A, Jones DA, Myburgh JA, Syres GA, Webb SA, Williams P: Australasian resuscitation of sepsis evaluation (ARISE): a multi-centre, prospective, inception cohort study. Resuscitation 2009, 80:811-818.

64. Reade MC, Huang DT, Bell D, Coats TJ, Cross AM, Moran JL, Peake SL, Singer $M$, Yealy DM, Angus DC: Variability in management of early severe sepsis. Emerg Med J 2010, 27:110-115.

65. The ProCESS Investigators: A randomized trial of protocol-based care for early septic shock. N Engl J Med 2014, 370:1683-1693.

66. Harris T, Thomas GO, Brohi K: Early fluid resuscitation in severe trauma. BMJ 2012, 345:e5752.

67. Ley EJ, Clond MA, Srour MK, Barnajian M, Mirocha J, Margulies DR, Salim A: Emergency department crystalloid resuscitation of $1.5 \mathrm{~L}$ or more is associated with increased mortality in elderly and nonelderly trauma patients. J Trauma 2011, 70:398-400.

68. Wang $\mathrm{CH}$, Hsieh WH, Chou HC, Huang YS, Shen JH, Yeo YH, Chang HE: Liberal versus restricted fluid resuscitation strategies in trauma patients: a systematic review and meta-analysis of randomized controlled trials and observational studies. Crit Care Med 2014, 42:954-962.

69. de-Madaria E, Soler-Sala G, Sanchez-Paya J, Lopez-Font I, Martinez J, GomezEscolar L, Sempere L, Sanchez-Fortun C, Perez-Mateo M: Influence of fluid therapy on the prognosis of acute pancreatitis: a prospective cohort study. Am J Gastroenterol 2011, 106:1843-1850.

70. Bellomo R, Warrillow SJ, Reade MC: Why we should be wary of singlecenter trials. Crit Care Med 2009, 37:3114-3119.

71. Marik PE: Surviving sepsis: going beyond the guidelines. Ann Intensive Care 2011, 1:17.

72. Burton TM: New therapy for sepsis infection raises hope but many questions (lead article). Wall St J 2008, Page 1, August 14 2008.
73. Marik PE, Monnet $X$, Teboul JL: Hemodynamic parameters to guide fluid therapy. Ann Crit Care 2011, 1:1

74. Marik PE, Lemson J: Fluid responsiveness: an evolution of our understanding. Br J Anaesth 2014, 112:620-622.

75. Marik PE, Cavallazzi R: Does the Central Venous Pressure (CVP) predict fluid responsiveness: an update meta-analysis and a plea for some common sense. Crit Care Med 2013, 41:1774-1781.

76. Mullens W, Abrahams Z, Francis GS, Sokos G, Taylor DO, Starling RC, Young $J B$, Tang WH: Importance of venous congestion for worsening of renal function in advanced decompensated heart failure. J Am Coll Cardiol 2009, 53:589-596

77. Bayliss WM, Starling EH: Observations on venous pressures and their relationship to capillary pressures. J Physiol 1894, 16:159-318.

78. Guyton AC: Determination of cardiac output by equating venous return curves with cardiac response curves. Physiol Rev 1955, 35:123-129.

79. Peters J, Mack GW, Lister G: The importance of the peripheral circulation in critical illnesses. Intensive Care Med 2001, 27:1446-1458.

80. Gelman S: Venous function and central venous pressure: a physiologic story. Anesthesiol 2008, 108:735-748.

81. Funk DJ, Jacobsohn E, Kumar A: The role of venous return in critical illness and shock - part I: physiology. Crit Care Med 2013, 41:250-257.

82. Cecconi M, Aya HD, Geisen M, Ebm C, Fletcher N, Grounds RM, Rhodes A Changes in the mean systemic filling pressure during a fluid challenge in postsurgical intensive care patients. Intensive Care Med 2013, 39:1299-1305.

83. Prowle JR, Kirwan CJ, Bellomo R: Fluid management for the prevention and attenuation of acute kidney injury. Nat Rev Nephrol 2014, 10:37-47.

84. Rohn DA, Stewart RH, Elk JR, Laine GA, Drake RE: Renal lymphatic function following venous pressure elevation. Lymphology 1996, 29:67-75.

85. Nohria A, Hasselblad V, Stebbins A, Pauly DF, Fonarow GC, Shah M, Yancy CW, Califf RM, Stevenson LW, Hill JA: Cardiorenal interactions: insights from the ESCAPE trial. J Am Coll Cardiol 2008, 51:1268-1274.

86. Lorenzo M, Davis JW, Negin S, Kaups K, Parks S, Brubaker D, Tyroch A: Can Ringer's lactate be used safely with blood transfusions? Am J Surg 1998, 175:308-310.

87. Wilcox CS: Regulation of renal blood flow by plasma chloride. J Clin Invest 1983, 71:726-735.

88. Chowdhury AH, Cox EF, Francis S, Lobo DN: A randomized, controlled, double-blind crossover study on the effects of 2 -L infusions of $0.9 \%$ saline and plasma-lyte 148 on renal blood flow velocity and renal cortical tissue perfusion in healthy volunteers. Ann Surg 2012, 256:18-24

89. Scheingraber S, Rehm M, Sehmisch C, Finsterer U: Rapid saline infusion produces hyperchloremic acidosis in patients undergoing gynecologic surgery. Anesthesiol 1999, 90:1265-1270.

90. Kellum JA, Bellomo R, Kramer DJ, Pinsky MR: Etiology of metabolic acidosis during saline resuscitation in endotoxemia. Shock 1998, 9:364-368.

91. Waters JH, Gottlieb A, Schoenwald P, Popovich MJ, Sprung J, Nelson DR: Normal saline versus lactated Ringer's solution for intraoperative fluid management in patients undergoing abdominal aortic aneurysm repair: an outcome study. Anesth Analg 2001, 93:817-822.

92. Reid F, Lobo DN, Williams RN, Rowlands BJ, Allison SP: (Ab)normal saline and physiological Hartmann's solution: a randomized double-blind crossover study. Clin Sci 2003, 104:17-24.

93. Kellum JA, Song M, Almasri E: Hyperchloremic acidosis increases circulating inflammatory molecules in experimental sepsis. Chest 2006 130:962-967.

94. Wu BU, Hwang JQ, Gardner TH, Repas K, Delee R, Yu S, Smith B, Banks PA, Conwell DL: Lactated Ringer's solution reduces systemic inflammation compared with saline in patients with acute pancreatitis. Clin Gastroenterol Hepatol 2011, 9:710-717

95. Boniatti MM, Cardoso PR, Castilho RK, Vieira SR: Is hyperchloremia associated with mortality in critically ill patients? A prospective cohort study. J Crit Care 2011, 26:175-179.

96. Stanley WC, Stanley WC: Myocardial lactate metabolism during exercise. Med Sci Sports Exerc 1991, 23:920-924.

97. Lopaschuk GD, Ussher JR, Folmes CD, Jaswal JS, Stanley WC: Myocardial fatty acid metabolism in health and disease. Physiol Rev 2010, 90:207-258.

98. Kline JA, Thornton LR, Lopaschuk GD, Barbee RW, Watts JA: Lactate improves cardiac efficiency after hemorrhagic shock. Shock 2000, 14:215-221.

99. Revelly JP, Tappy L, Martinez A, Bollmann M, Cayeux MC, Berger MM, Chiolero RL: Lactate and glucose metabolism in severe sepsis and cardiogenic shock. Crit Care Med 2005, 33:2235-2240. 
100. Van Hall G, Stromstad M, Rasmussen P, Jans O, Zaar M, Gam C, Quistorff B, Secher $\mathrm{NH}$, Nielsen HB: Blood lactate is an important energy source for the human brain. J Cereb Blood Flow Metab 2009, 29:1121-1129.

101. Quistorff B, Secher NH, Van Lieshout JJ: Lactate fuels the human brain during exercise. FASEB J 2008, 22:3443-3449.

102. Wyss MT, Jolivet R, Buck A, Magistretti PJ, Weber B: In vivo evidence for lactate as a neuronal energy source. J Neurosci 2011, 31:7477-7485.

103. Garcia-Alvarez M, Marik PE, Bellomo R: Stress hyperlactemia. Lancet Endo Diabetes 2013, doi:org/10.1016/S2213-8587(13)70154-2.

104. White SA, Goldhill DR, White SA, Goldhill DR: Is Hartmann's the solution? Anaesthesia 1997, 52:422-427.

doi:10.1186/s13613-014-0021-0

Cite this article as: Marik: latrogenic salt water drowning and the hazards

of a high central venous pressure. Annals of Intensive Care 2014 4:21.

\section{Submit your manuscript to a SpringerOpen ${ }^{\circ}$} journal and benefit from:

- Convenient online submission

- Rigorous peer review

- Immediate publication on acceptance

- Open access: articles freely available online

- High visibility within the field

- Retaining the copyright to your article

Submit your next manuscript at springeropen.com 